\title{
Numerical Estimation of Shallow Water Resistance of a River-Sea Ship using CFD
}

\author{
Senthil Prakash M.N,Ph.D \\ Associate Professor \\ Department of Mechanical \\ Engineering,CUSAT \\ CUCEK, Alappuzha-688504, India
}

\author{
Binod Chandra \\ $M$ Tech CASAD \\ Department of Ship Technology \\ Cochin University of Science and \\ Technology,
}

Cochin-682022, India

\begin{abstract}
In recent years a great deal of research efforts in ship hydromechanics have been devoted to practical navigation problems in moving larger ships safely into existing harbours and inland waterways and to ease congestion in existing shipping routes. The starting point of any navigational or design analysis lies in the accurate determination of the hydrodynamic forces generated on the ship hull moving in confined waters. The analysis of such ship motion should include the effects of shallow water. An area of particular interest is the determination of ship resistance in shallow or restricted waters at different speeds, forming the basis for the power calculation and design of the propulsion system. The present work describes the implementation of CFD techniques for determining the shallow water resistance of a river-sea ship at different speeds. The ship hull flow is analysed for different ship speeds in shallow water conditions. The results obtained from CFD analysis are compared with available standard results.
\end{abstract}

\section{General Terms}

hull resistance, wave pattern, squat, Computational Fluid Dynamics (CFD), Schlichting's method.

\section{Keywords}

Restricted water, River-sea ship, mesh, domain, shallow water depth, surface wave pattern, hull drag.

\section{INTRODUCTION}

The components of ship resistance and their behavior form a significant aspect in ship hydrodynamics. The resistance of a ship at a given speed is the fluid force acting on the ship in such away as to oppose its forward motion. It can be defined as the force required to tow the ship at a particular speed in smooth water, assuming no interference from the towing ship. The resistance estimates are subsequently used in estimating the required propulsive power and design of the propulsion system.

Scientific interest in the effect of shallow or confined waters on the resistance of ships has existed long before but has become more intense in the recent years with growth in ship size and added congestion of the shipping routes. The resistance of a ship is quite sensitive to effects of shallow water. The potential flow around the hull changes appreciably. If the ship is considered as being at rest in a flowing stream of restricted depth, but unrestricted width, the water passing below it must speed up more than in deep water, with a

consequent greater reduction in pressure and increased sinkage, trim and resistance. Furthermore if it is restricted laterally, as in a river or canal, these effects are exaggerated. The sinkage and trim in very shallow water can set an upper limit to the speed at which ships can operate without grounding. Also the wave pattern created by the moving ship changes in shallow water, leading to a change in the wave making resistance.

The application of CFD techniques have rapidly advanced to a stage that it is capable of computing hull resistance with sufficient accuracy. One of the main advantages of CFD techniques is that it acts as an efficient supplementary tool to costly model tests.

\section{HULL RESISTANCE AND SURFACE WAVE PATTERN}

\subsection{Hull Resistance}

Water resistance of a ship can be divided into Frictional resistance $R_{f}$ and Residuary resistance $R_{r}$.

Frictional Resistance arises due to motion of hull through viscous fluid. The fore and aft components of the tangential shear forces $\tau$ acting on each element of the hull can be summed over the hull to obtain the total shear resistance or frictional resistance.

Residuary Resistance can be divided into different components as follows:

i. Wave Making Resistance

Wave Making Resistance $R_{w}$ which is caused due to energy that is continuously supplied by the ship to the wave system created on the surface of water. The wave making resistance is the net fore and aft force upon the ship due to the fluid pressures acting normally on all parts of the hull. If body is travelling on or near the surface, the variation in pressure causes waves which alter the distribution of pressure over the hull and the resultant net fore and aft force is the wave making resistance.

\section{ii. Viscous Pressure Resistance}

Viscous Pressure Resistance is caused by the difference between the stagnation pressures at bow and stern due to loss of energy in the boundary layer in overcoming the tangential shear forces. This results in a reduced stagnation pressure at the stern. The integration of the fore-aft components of the normal pressure forces around the hull yields a net force against direction of motion called viscous pressure resistance. iii. Separation and Eddy Resistance

Separation and Eddy Resistance occur due to the energy carried away by eddies shed from the hull or appendages. Local eddying will occur behind appendages such as bossings, 
shafts and shaft struts and from stern frames and rudders if these items are not properly streamlined and aligned with the flow. Also, if the after end of the ship is too blunt, the water may be unable to follow the curvature and will break away from the hull, giving rise to eddies and separation resistance.

iv. Augmented Resistance due to the 3-D Curvature of the ship which is the increase in frictional resistance of a 3-D body in viscous fluid as compared to a 2-D body.

\section{v. Air Resistance}

Air Resistance is experienced by the above-water part of the main hull and the superstructures due to the motion of the ship through the air. It becomes more significant in high speed ships having larger superstructures..

\subsubsection{Hull resistance in Shallow water}

As the ship enters water of restricted depth, termed shallow water, a number of changes occur due to the interaction between the ship and the seabed.

- Due to constriction between the hull bottom and sea/river bed, potential flow velocity increases between hull bottom and sea/river bed. The consequent reduction in pressure around the hull leads to reduction in buoyancy and change in centre of buoyancy. The ship is then subjected to sinkage and change in trim.

- Increase in total water resistance. Increase in potential flow velocity causes increase in frictional resistance. Change in wave pattern causes increase in wave making resistance at sub critical speeds.

If in addition the water is restricted laterally, as in a river or canal, these effects are further exaggerated. The sinkage and trim in very shallow water may set an upper limit to the speed at which the ships can operate without grounding.

\subsection{SURFACE WAVE PATTERN}

In deep water, the wave pattern consists of transverse and diverging waves as shown in Fig 1 (Molland, Turnock, Hudson; 2001).The pattern being contained between the straight lines makes an angle of $19.47^{\circ}$ on each side of the line of motion of the point. Change in wave pattern occurs in passing from deep to shallow water.

\subsubsection{Wave Pattern in Shallow water}

Categorization of water as deep, intermediate or shallow is based on the ratio of water depth to wavelength $h / \lambda$, where $h$ is the water depth and $\lambda$ is the wave length.

In shallow water as $h / \lambda$ is small, the velocity of propagation of the wave, commonly called celerity, is given by

$$
C=\sqrt{g h}
$$

where $\mathrm{g}$ is the acceleration due to gravity.

$$
\mathrm{h} \text { is the water depth. }
$$

The velocity now depends only on the water depth and waves of different wavelength propagate at the same speed called Critical Speed.

Since the waves travel in the same velocity $\mathrm{C}$ as the ship speed V, speed ranges can be taken in terms of depth Froude number. The depth Froude number is defined as

$$
F r_{h}=\frac{V}{\sqrt{g h}}
$$

The speeds below and above $C=\sqrt{g h}$ are known as the sub critical speeds and super critical speeds respectively. At speeds well below $\mathrm{Fr}_{h}=1.0$ i.e. critical speed, the wave system is as shown in Fig 3 with a transverse wave system and a divergent wave system propagating away from the ship at an angle of about $35^{\circ}$. As the ship speed approaches the critical speed, $\mathrm{Fr}_{\mathrm{h}}=1.0$, the wave angle approaches $0^{\circ}$, or perpendicular to the track of ship as shown in Fig 2 (PNA Vol 2 , 1988). At speeds greater than the critical speed, the diverging wave system returns to a wave propagation angle of about $\cos ^{-1}\left(1 / \mathrm{Fr}_{h}\right)$ and transverse waves do not exist.

\subsection{SHIP SQUAT}

As a ship proceeds through shallow water there is an increase in flow speed, back flow, under the vessel and a drop in pressure. This drop in pressure leads to squat which is made up of vertical sinkage together with trim by the bow or stern. For a vessel moving too fast in shallow water, squat can lead to loss of underkeel clearance and possible grounding. Several investigations into squat have been carried out effectively (Dand and Ferguson, 1973). A much simpler formula has been obtained (Barass and Derrett, 2006) for estimating maximum squat in a confined channel such as a river.

$$
\delta_{\max }=\frac{C_{B} S_{B}^{0.81} \cdot V_{S}^{2.08}}{20} \mathrm{~m}
$$

where $C_{B}$ is block coefficient, $S_{B}$ is a blockage factor, being the ratio of the ship's cross section to the cross section of the channel., and $\mathrm{V}_{\mathrm{s}}$ is the speed ship in knots.

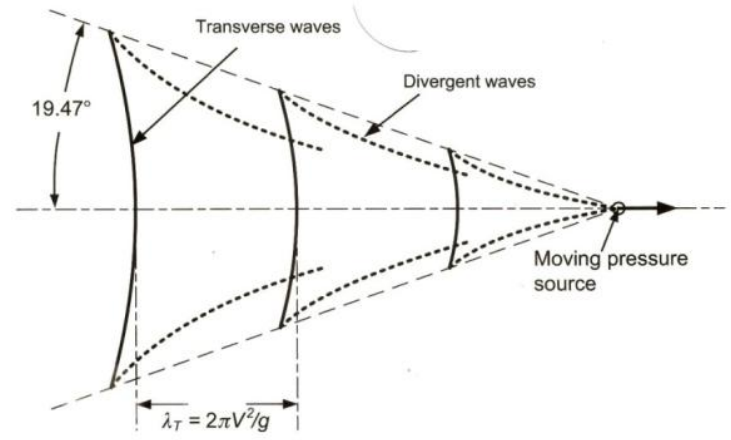

Fig 1: Kelvin wave pattern 


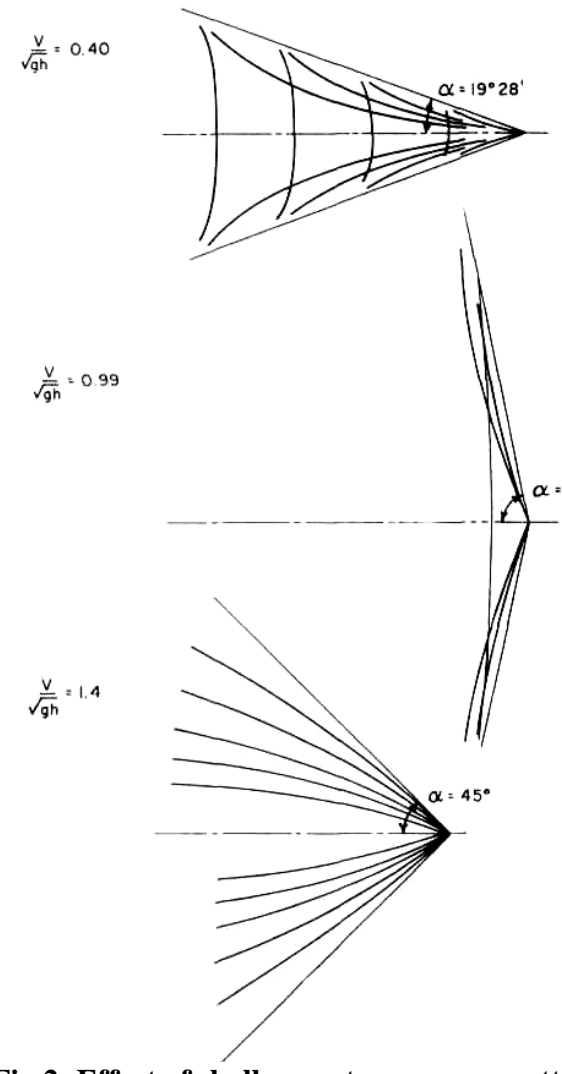

Fig 2: Effect of shallow water on wave pattern

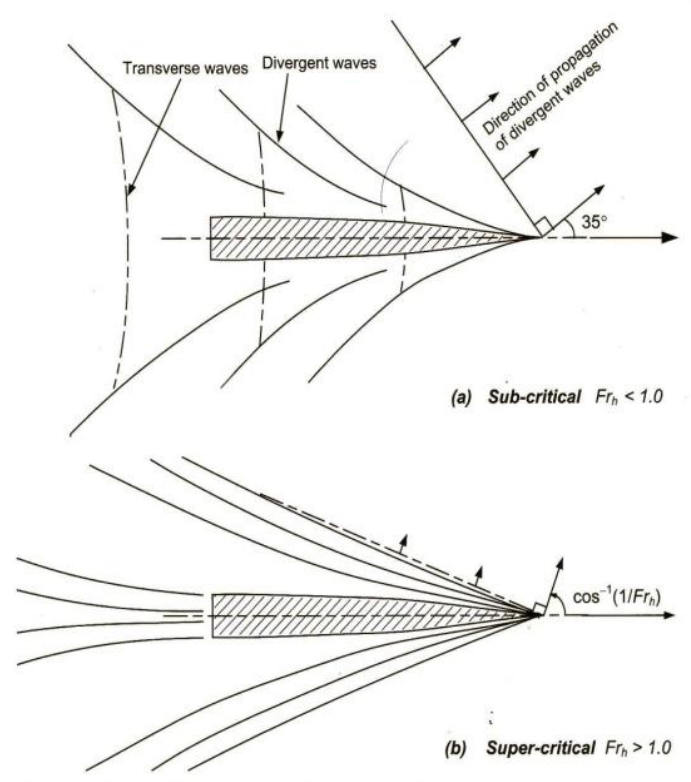

Fig 3: Sub-critical and supercritical wave patterns

\section{CFD SIMULATION OF THE HULL IN SHALLOW WATER}

Towing tank tests for determination of hull resistance can be supplemented by the CFD techniques with the advantage that CFD techniques can be directly applied on the prototype. The first step of the CFD simulation is to prepare the CAD geometry of the hull which is described in the section below.

\subsection{Hull geometry}

The CFD analysis scheme can be classified as preprocessing, processing and post processing. The preprocessing stage includes preparing the geometry in CAD. This is prepared based on the offset table following the data in Table 4. The 3D shape of the bare hull of the river-sea ship selected for analysis is shown in Fig 4.

Table 1 Particulars of Hull geometry

\begin{tabular}{|l|l|l|}
\hline \multicolumn{2}{|l|}{ Main particulars } & Full scale \\
\hline Length on waterline & $\mathrm{L}_{\mathrm{WL}}(\mathrm{m})$ & 88.67 \\
\hline Maximum beam on waterline & $\mathrm{B}_{\mathrm{WL}}(\mathrm{m})$ & 16.0 \\
\hline Depth & $\mathrm{D}(\mathrm{m})$ & 4.0 \\
\hline Draft ( Full Load) & $\mathrm{T}(\mathrm{m})$ & 2.5 \\
\hline Displacement & & \\
\hline Block coefficient $\left(\mathrm{C}_{\mathrm{B}}\right)$ & $\nabla /(\mathrm{t})$ & 2950 \\
\hline
\end{tabular}

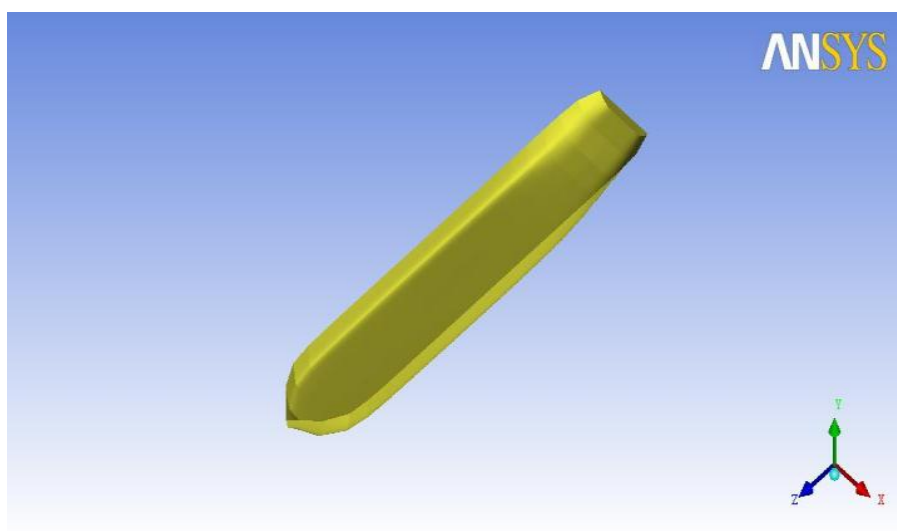

Fig 4: Ship hull

The medium in which the ship is moving is known as the domain. The domain dimensions (width and depth) around the ship hull are determined matching the actual physical conditions and the dimensions upstream and downstream the hull is decided following ITTC recommendations. A pictorial representation of the domain with the ship is shown in Fig. 5 


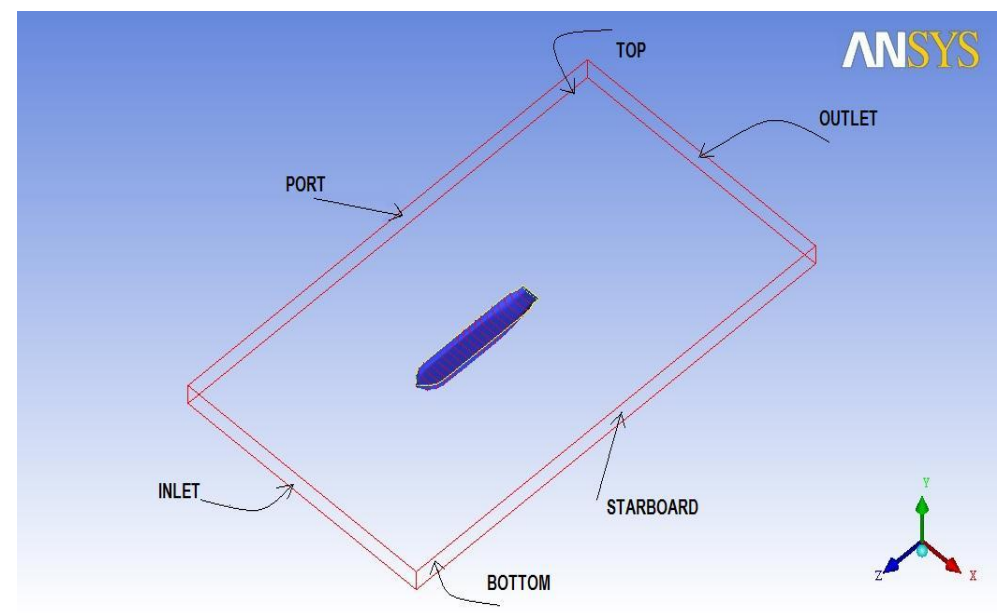

Fig 5: Domain for the ship hull

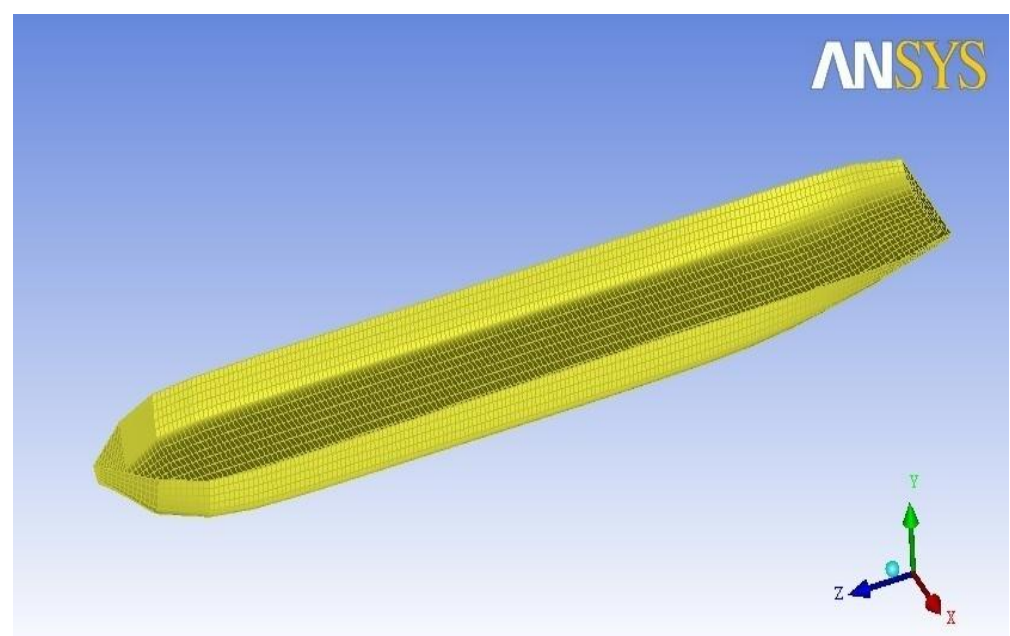

Fig 6: Surface meshes on the hull

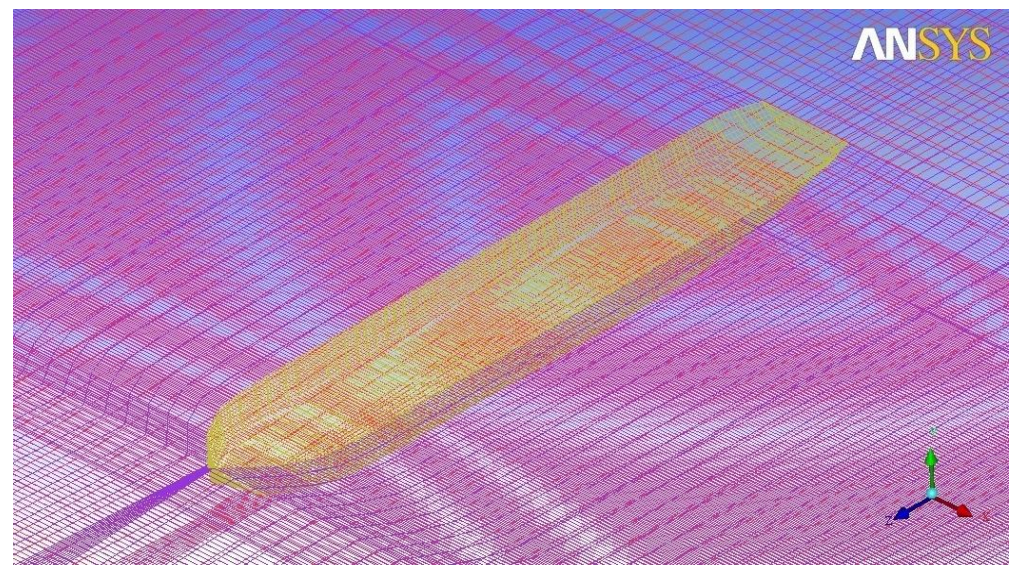

Fig 7: Hull and domain discretized with structured mesh 


\subsection{COMPUTATIONAL DOMAIN}

The domain dimensions for computation are fixed with respect to a local coordinate system with origin at the meeting point of midsection, central plane of ship and free surface and are given below.

$$
\begin{gathered}
1.9<\mathrm{z} / \mathrm{L}_{\mathrm{pp}}<-2.5, \\
-1<\mathrm{x} / \mathrm{L}_{\mathrm{pp}}<1, \\
-0.0338<\mathrm{y} / \mathrm{L}_{\mathrm{pp}}<0.017
\end{gathered}
$$

\subsubsection{Domain discretization}

The domain around the hull is discretized with 3D hexahedral structured mesh using ANSYS ICEM CFDThe procedure of descretization with structured mesh in the software involves the following steps:

1. Creating a block in the domain, which is basically a single mesh covering the whole domain.

2. Splitting this block in to smaller blocks

3. Removing blocks from the no flow region.

4. Associating the block edges, vertices and faces with the geometry curves, points and surfaces accordingly.

5. Mesh density is controlled by assigning number of meshes on each of the edges. A grading of mesh density to provide denser meshes near the hull is done by applying proper mesh law. This is done to to capture the boundary layer effects near the hull. Fig. 6 shows the surface meshes on the hull and Fig. 7 shows 3D structured meshes in the domain.

\subsection{SOLVER EXECUTION}

The steps listed so far comes under the preprocessing stage. The discretized domain is solved in the solver for obtaining flow properties. The solver used here is Fluent. For accurate results after the solutions a correct selection of solver parameters is essential. The solver settings used for the current simulation is shown in Table 2.

\subsubsection{Selection of turbulence Model}

The closure of the RANSE solution is obtained by applying suitable turbulence model. Hence successful modeling of turbulence greatly increases the quality of numerical simulations. From the past experiences, for flow around the hull, it is observed that SST K- $\omega$ turbulence model, which is a combination of $\mathrm{K}-\epsilon$ and $\mathrm{K}-\omega$ model simulates the flow more accurately. Selection of other parameters are also done from reported results in publications and are given in Table 2.

\subsection{POST PROCESSING}

In post processing the desired information is extracted from the data set generated by the CFD code. Versatile visualization tools are an added advantage of CFD packages. After analysis the results obtained is represented in tabular, graphical and contour plots in the post processing stage.
Table 2 Summary of parameters selected for simulation

\begin{tabular}{|c|c|l|l|l|}
\hline $\begin{array}{l}\text { SI } \\
\text { No }\end{array}$ & Description & $\begin{array}{l}\text { Sub } \\
\text { Critical } \\
\text { speed }\end{array}$ & $\begin{array}{l}\text { Critical } \\
\text { Speed }\end{array}$ & $\begin{array}{l}\text { Super } \\
\text { Critical } \\
\text { speed }\end{array}$ \\
\hline 1. & solver & \multicolumn{3}{|c|}{ PISO } \\
\hline 2. & Turbulence & \multicolumn{3}{|c|}{ SST K- $\omega$} \\
\hline 3. & $\begin{array}{c}\text { Flow } \\
\text { velocity(air } \\
\text { inlet) }\end{array}$ & $3.0 \mathrm{~m} / \mathrm{s}$ & $5.4 \mathrm{~m} / \mathrm{s}$ & $7 \mathrm{~m} / \mathrm{s}$ \\
\hline 4. & $\begin{array}{c}\text { Flow } \\
\text { velocity(water } \\
\text { inlet) }\end{array}$ & $3.0 \mathrm{~m} / \mathrm{s}$ & $5.4 \mathrm{~m} / \mathrm{s}$ & $7 \mathrm{~m} / \mathrm{s}$ \\
\hline 5. & $\begin{array}{c}\text { Mesh } \\
\text { Structured mesh }\end{array}$ \\
\hline 6. & $\begin{array}{l}\text { Material } \\
\text { properties } \\
\text { (Water) } \\
\text { Density }\end{array}$ & $1000 \mathrm{~kg} / \mathrm{m} 3$ \\
Viscosity & $1.78 \mathrm{E}-05 \mathrm{~kg} / \mathrm{m}-\mathrm{s}$ \\
\hline
\end{tabular}

\section{SHALLOW WATER RESISTANCE PREDICTION USING SCHLICHTING'S METHOD}

An analysis of shallow-water effects was made by Schlichting (1934). It covered the increase in resistance in shallow water at subcritical speeds and was for shallow water of unlimited lateral extent (PNA Vol2, 1988). The analysis was based on theoretical considerations and on model experiments carried out in the Hamburg and Vienna tanks.Typical frictional and total resistance curves for deep water to a base of speed are shown in Figure 8.

At any particular speed $V_{\infty}$ in deep water, frictional resistance and total resistance are $\mathrm{R}_{\mathrm{F}}$ and $\mathrm{R}_{\mathrm{T}}$ respectively. At this speed the wave pattern generated by the ship will have a wavelength $\mathrm{L}_{\mathrm{W}}$ given by

$$
\mathrm{V}_{\infty}^{2}=\mathrm{gL}_{\mathrm{W}} / 2 \pi
$$

In water of depth $h$ the same wave length $L_{w}$ would be generated at some lower or intermediate speed $V_{I}$ where

$$
\mathrm{V}_{\mathrm{I}}^{2}=\left(\mathrm{g} \mathrm{L}_{\mathrm{W}} / 2 \pi\right) \tanh 2 \pi \mathrm{h} / \mathrm{L}_{\mathrm{W}}
$$

And the ratio of the two speeds is

$$
\begin{aligned}
& \mathrm{V}_{\mathrm{I}} / \mathrm{V}_{\infty}=\left(\tanh 2 \pi \mathrm{h} / \mathrm{L}_{\mathrm{W}}\right)^{1 / 2} \\
& \mathrm{~V}_{\mathrm{I}} / \mathrm{V}_{\infty}=\left(\tanh \mathrm{gh} / \mathrm{V}_{\infty}{ }^{2}\right)^{1 / 2}
\end{aligned}
$$


A curve of $\mathrm{V}_{\mathrm{I}} / \mathrm{V}_{\infty}$ to the base of $\mathrm{V}_{\infty} / \sqrt{g h}$ is shown in Figure 9.

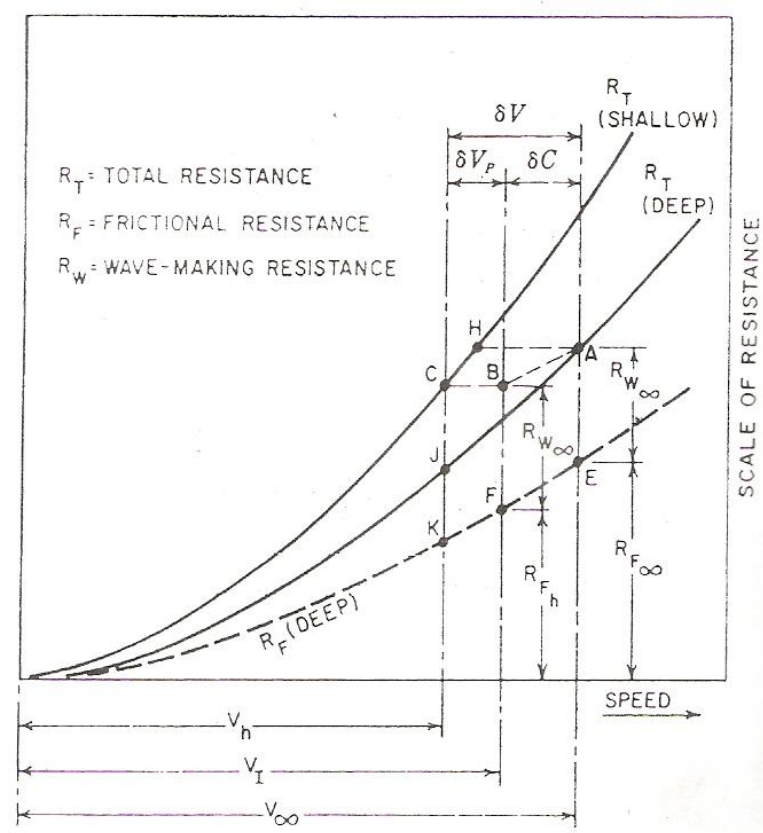

Fig 8: Determination of shallow water resistance by Schlichting's method

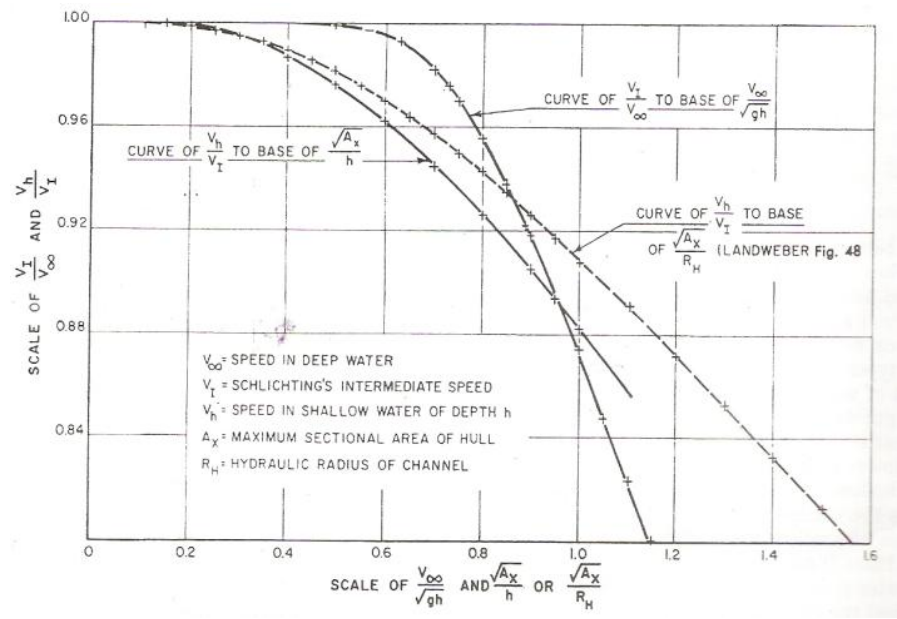

Fig 9: Curves of velocity ratios for calculating resistance in shallow water

The reduction in speed on this account in Fig. 8 is given by

$$
\mathrm{V}_{\infty}-\mathrm{V}_{\mathrm{I}}=\delta \mathrm{C}
$$

Schlichting assumed that the wave-making resistance in shallow water at speed $V_{I}$ would be the same as that at speed $\mathrm{V}_{\infty}$ in deep water. The total resistance at speed $\mathrm{V}_{\mathrm{I}}$ can be found at point $B$ by adding the wave-making resistance $R_{W_{\infty}}$ to the appropriate frictional resistance at this speed $\mathrm{R}_{\mathrm{Fh}}$. There is a further loss in speed $\delta \mathrm{V}_{\mathrm{p}}$ because of the increase in potential flow around the hull due to the restriction of area by proximity of the bottom, giving the final speed as

$$
\mathrm{V}_{\mathrm{h}}=\mathrm{V}_{\mathrm{I}}-\delta \mathrm{V}_{\mathrm{p}}
$$

Schlichting investigated this reduction in speed and found that principal factor controlling $\delta \mathrm{V}_{\mathrm{p}}$ was the ratio

$$
\sqrt{A x} / h
$$

where $\mathrm{A} x=$ maximum cross-sectional area of the hull

$$
\mathrm{h}=\text { depth of water }
$$

Figure 9 shows the curve of $\mathrm{V}_{\mathrm{h}} / \mathrm{V}_{\mathrm{I}}$ against $\sqrt{A x} / h$ derived by Schlichting from his model tests and also the relation between $\mathrm{V}_{\mathrm{I}}$ and $\mathrm{V}_{\infty}$ for different depths of water $\mathrm{h}$.

It can be found that at point $\mathrm{C}$ in Fig.10,the total resistance in shallow water at speed $V_{h}$ is less than that in deep water at speed $V_{\infty}$ ie point $A$. Hence to find the speed in shallow water for the same total resistance, will be given by the point $\mathrm{H}$. The total speed loss is given by the equation

$$
\delta \mathrm{V}=\delta \mathrm{C}+\delta \mathrm{V}_{\mathrm{p}}
$$

Schlichting's work is not theoretically rigorous, but can be looked upon as good solution to the complicated problem. The method is effective in obtaining the shallow water resistance at sub-critical speeds.

\section{RESULTS AND DISCUSSION}

Simulations were done for the selected hull at the speeds of $1.55 \mathrm{~m} / \mathrm{s}, 3 \mathrm{~m} / \mathrm{s}, 3.6 \mathrm{~m} / \mathrm{s}, 4.11 \mathrm{~m} / \mathrm{s}, 4.6 \mathrm{~m} / \mathrm{s}, 5.4 \mathrm{~m} / \mathrm{s}, 7 \mathrm{~m} / \mathrm{s}$ for a water depth of $3 \mathrm{~m}$ which includes sub-critical, critical and super-critical conditions. The pressure magnitudes obtained in the simulation have been represented as contour plots with a color scale as shown in Fig.10. The obtained results were found to be in close agreement with the wave pattern formed at respective speeds ie sub critical, critical and supercritical.

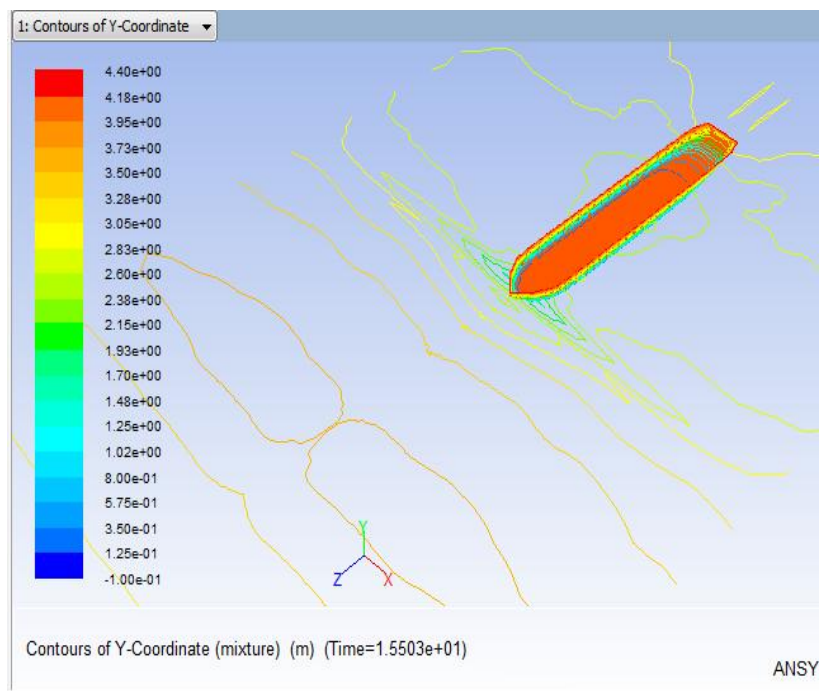


Fig 10: Wave pattern created by the hull at subcritical speed of $1.55 \mathrm{~m} / \mathrm{s}$ ( 3 knots)
Figure 12 shows the wave pattern obtained for the ship hull at the critical speed of $5.4 \mathrm{~m} / \mathrm{s}$. The obtained results were compared with shallow water wave pattern given in (PNA Vol 2, 1988) [Fig 2] which showed general agreement.

The total drag at various simulated speeds is shown in

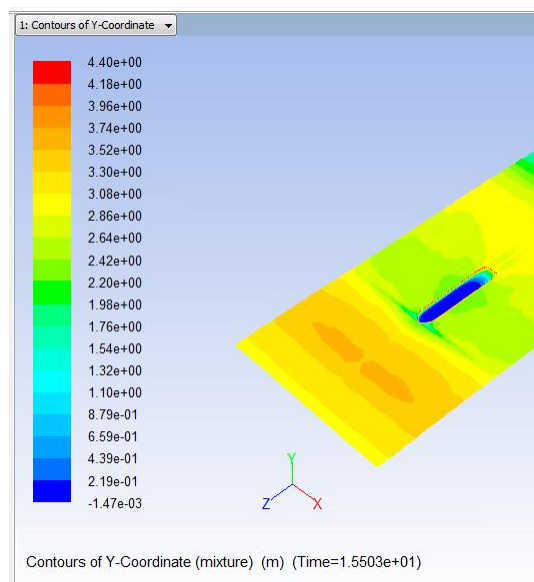

\section{MNSYS}

Table 4 Summary of parameters selected for simulation

Fig 11: Wave pattern created by the hull at subcritical speed of $3 \mathrm{~m} / \mathrm{s}$ (5.83 knots)
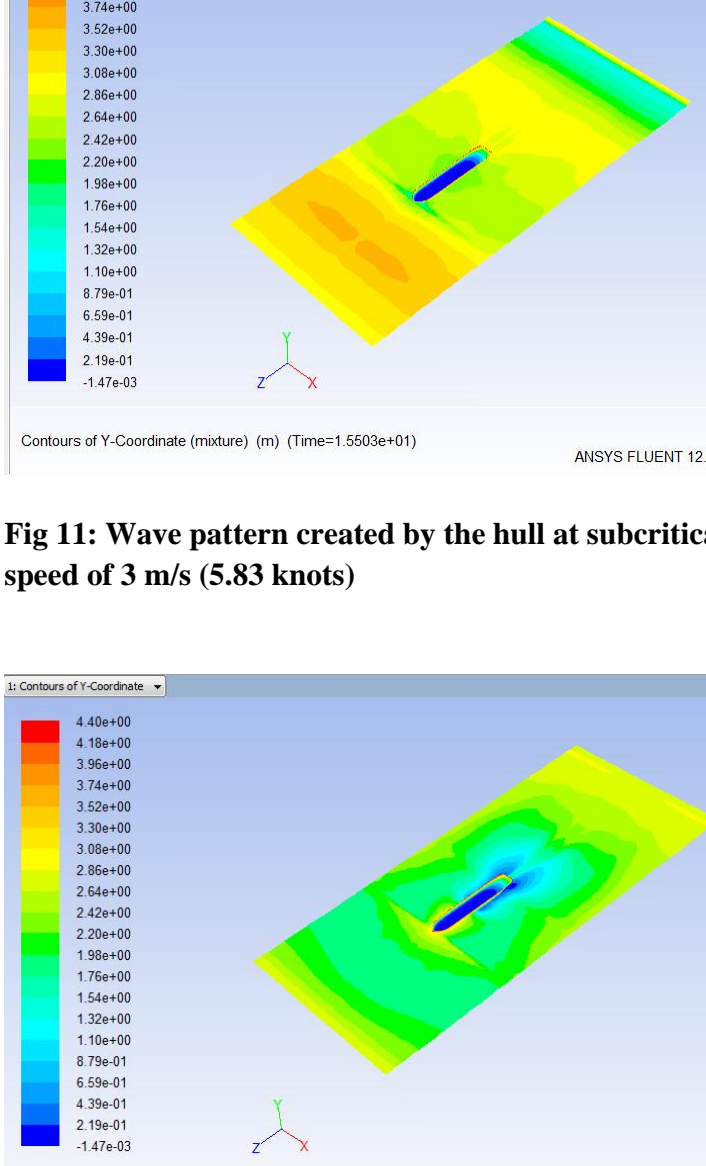

Speed

\begin{tabular}{|c|c|c|c|c|}
\hline $\begin{array}{l}\text { Speed } \\
(\mathrm{m} / \mathrm{s})\end{array}$ & Region & $\begin{array}{l}\text { Total Drag } \\
\text { (CFD) }\end{array}$ & $\begin{array}{l}\text { Total Drag } \\
\text { (Schlichting) }\end{array}$ & $\begin{array}{c}\text { Difference } \\
\%\end{array}$ \\
\hline 1.55 & Subcritical & $57.80 \quad \mathrm{kN}$ & $50.81 \mathrm{kN}$ & 12.09 \\
\hline 3 & Subcritical & $72.582 \mathrm{kN}$ & $74.42 \mathrm{kN}$ & 2.53 \\
\hline 3.6 & Subcritical & $103.47 \mathrm{kN}$ & $101.37 \mathrm{kN}$ & 2.03 \\
\hline 4.11 & Subcritical & $140.36 \mathrm{kN}$ & $137.83 \mathrm{kN}$ & 1.80 \\
\hline 4.6 & Subcritical & $198.5 \mathrm{kN}$ & $191.63 \mathrm{kN}$ & 3.46 \\
\hline 5.4 & Critical & $340.5 \mathrm{kN}$ & - & - \\
\hline 7 & Supercritical & $1032.5 \mathrm{kN}$ & - & - \\
\hline
\end{tabular}

The velocity magnitude in the domain around the hull during simulation is represented as contour plot in Figure 13. As predicted increased potential flow velocity between the hull and the river bottom is observed.

Fig.12 Wave pattern created by the hull at critical speed of $5.4 \mathrm{~m} / \mathrm{s}$ (10.5 knots)
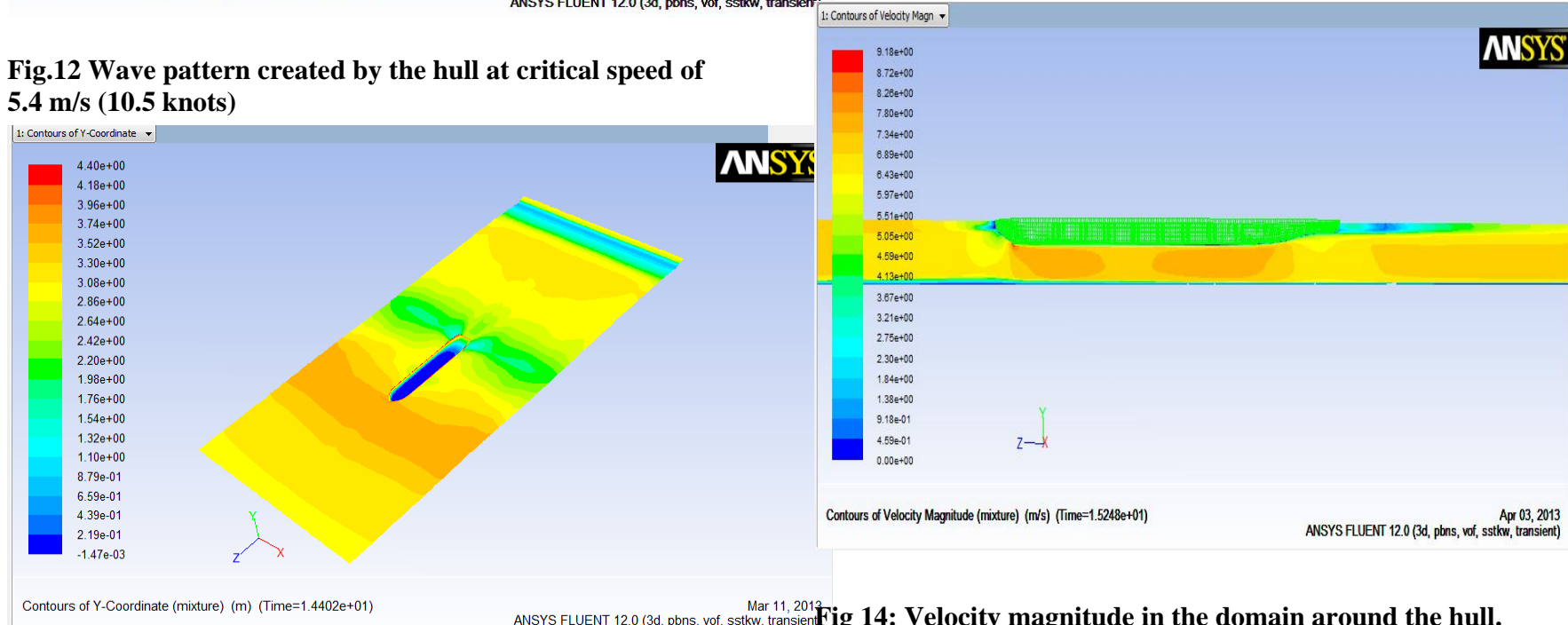

ig 14: Velocity magnitude in the domain around the hull.

Fig 13: Wave pattern created by the hull at supercritical speed of $7 \mathrm{~m} / \mathrm{s}$ (13.6 knots)
In the present study, the resistance for deep water was estimated using the Holtrop method (Holtrop, 1978 ). The 
shallow water resistance curve was then obtained from the deep water resistance curve using Schlichting's method (PNA Vol 2, 1988).

The total drag at different speeds for a water depth of $3 \mathrm{~m}$ was estimated by Schlichting's method, using NavCad software. The results are shown in Table 4.

\section{SUMMARY AND CONCLUSIONS}

1. The hull was modeled in CAD based on the offset table and structured mesh was applied using ANSYS ICEM.

2. The flow around the hull was simulated using ANSYS FLUENT including the effect of free surface.

3. The Fig 12 shows the wave pattern created by the hull at the critical speed of $5.4 \mathrm{~m} / \mathrm{s}$. It can be seen that wave pattern formed is perpendicular to the track of ship, which is in agreement with the wave pattern for critical speed as given in (PNA Vol 2, 1988)

4. The obtained wave patterns at sub-critical, critical and super-critical speeds show general agreement with the theoretical predictions by Havelock (Havelock, 1908) as given in (PNA Vol 2, 1988).

5. The Fig 13 shows the contour plot of velocity magnitude around the hull. The increase in potential flow velocity between hull and river bottom as predicted theoretically is observed.

6. The shallow water resistance prediction was done using CFD and an empirical method formulated by (Schlichting, 1934). The results as shown in Table 4 show fairly good correlation at sub-critical speeds. The comparison has been limited to sub-critical speeds, since Schlichting's method covers only sub-critical speeds.

7. Overall it can be concluded that CFD can be effectively used for prediction of ship resistance at different speeds in shallow water. The time and expense of model testing can be considerably reduced by application of CFD.

\section{REFERENCES}

[1] Anderson, J .D. Computational fluid dynamics: The basics with applications, McGraw Hill, New York, 1995.

[2] Anthony, F.M., Turnock, S.R and Hudson, D.A. Ship resistance and propulsion: Practical Estimation of Ship propulsive power, Cambridge university press, 2011.

[3] Barrass, C.B. and Derrett, D.R. Ship Stability for Masters and Mates. Butterworth- Heinemann, Oxford, UK, 2006.

[4] Beck, R.F. and E.O. Tuck (1972) Computation of shallow water ship motions. Proceedings of $9^{\text {th }}$ Symposium on Naval Hydrodynamics, Paris, August, 63-85.
[5] Chen, X.-N. and Sharma, S.D. (1995) A slender ship moving at a near critical speed in a shallow channel, Journal of Fluid Mechanics, 291,263.

[6] Dand, I.W. and Ferguson, A.M. The squat of full ship in shallow water. Transactions of the Royal Institution of Naval Architects, Vol. 115, 1973, pp.237-255.

[7] E.V.Lewis,(ed.) Principles of Naval Architecture, Vol 2, SNAME, New York, 1988.

[8] Gourlay, T.P. (2006) Flow beneath a ship at small underkeel clearance. Journal of ship research, 50, 250258 .

[9] Gourlay, T.P. and Tuck, E.O. (2001) The maximum sinkage of a ship. Journal of ship research, 45, 1-50.

[10] Harvald, S.A. Resistance and Propulsion of ships, Wiley Interscience, New York, 1983.

[11]Havelock, T.H. (1908) The propagation of groups of waves in dispersive media, with application to waves produced by a travelling disturbance. Proceedings of the Royal Society, London, pp. 398-430.

[12] Hofman, M. and Kozarski, V.(1999) Shallow water resistance charts for preliminary vessel design. International Shipbuilding Progress, Vol 47, No.449, pp.61-66.

[13] Holtrop, J.(1978) A statistical power prediction method, International Shipbuilding Progress, 25, 35-69.

[14] ITTC (1999) The Resistance Committee final report and recommendations to the 22nd ITTC. Proceedings of 22nd International Towing Tank Conference, Seoul, Korea.

[15] Jachowski, J. Assessment of ship squat in shallow water using CFD. Archive Gdansk University of Technology, Vol 8, 2008, pp. 215-235.

[16] Jones, D.A. and D.B. Clarke (2010) Fluent code simulation of flow around a naval hull. Defence science and technology, 35, 17-19.

[17] Mei, C.C (1976) Flow around a thin body moving in shallow water, Journal of Fluid Mechanics, 96, 81.

[18] Millward, A. (1981) The effect of shallow water on the resistance of a ship at high sub critical and super critical speeds. Transactions of the Royal Institution of Naval Architects, Vol. 124, pp. 175-181.

[19] Millward, A. (1992) A comparison of the theoretical and empirical prediction of squat in shallow water. International Shipbuilding Progress, 417, 39-69.

[20]Tuck, E.O. (1966) Shallow water flows past slender bodies. Journal of Fluid Mechanics, 26,81.

[21]Tuck, E.O. (1964) A systematic asymptopic expansion procedure for slender ships. Journal of Ship Research, 8 , $15-23$. 